\title{
BMJ Open Extent of the association between self- rated health and place of birth: a cross- sectional study among people at high risk of developing pre-diabetes and diabetes in Sweden
}

\author{
Marina Taloyan (10 ,1,2 Amina Amri, ${ }^{3}$ Kristin Hjörleifsdottir Steiner, ${ }^{2}$ \\ Fahimeh Lamian, ${ }^{4}$ Claes-Goran Ostenson (D) , ${ }^{5}$ Helena Salminen ${ }^{2}$
}

To cite: Taloyan M, Amri A, Hjörleifsdottir Steiner K, et al. Extent of the association between self-rated health and place of birth: a cross-sectional study among people at high risk of developing pre-diabetes and diabetes in Sweden. BMJ Open 2019;9:e028757. doi:10.1136/ bmjopen-2018-028757

- Prepublication history for this paper is available online. To view these files, please visit the journal online (http://dx.doi org/10.1136/bmjopen-2018028757).

Received 06 February 2019 Revised 28 October 2019 Accepted 11 November 2019

Check for updates

(c) Author(s) (or their employer(s)) 2019. Re-use permitted under CC BY-NC. No commercial re-use. See rights and permissions. Published by BMJ.

For numbered affiliations see end of article.

Correspondence to

Dr Marina Taloyan;

marina.taloyan@sll.se

\section{ABSTRACT}

Objective The first aim was to determine the extent of the relationship between place of birth and self-rated health (SRH) in primary healthcare patients born outside Sweden and those born in Sweden. The second aim was to investigate whether socioeconomic and lifestyle factors explained any differences.

Setting Two academic primary healthcare centres in Stockholm County, Sweden.

Participants 825 patients at high risk of developing pre-diabetes and diabetes, aged 18-74 years, attending academic healthcare centres in areas with large numbers of immigrants, $56.8 \%$ born abroad and $43.2 \%$ born in Sweden. Patients with a diagnosis of diabetes were excluded. Inclusion criteria were based on previous research showing that people born in Middle Eastern and Asian countries who live in Sweden have a high prevalence of and risk for diabetes.

Outcome SRH was dichotomised as optimal (very good/ good) and suboptimal (fair/bad/very bad) and compared in those born outside Sweden and in Sweden.

Results There was a statistically significant difference in the SRH of the two groups $(p=0.008)$. Logistic regression analysis showed a crude OR for reduced SRH of $1.46(95 \%$ $\mathrm{Cl} 1.10$ to 1.92) in patients born outside Sweden. After controlling for education, employment and marital status, the OR increased to 1.50 (95\% $\mathrm{Cl} 1.11$ to 2.02). After controlling for physical activity and smoking, it decreased to $1.36(95 \% \mathrm{Cl} 1.00$ to 1.85$)$.

Conclusion Socioeconomic and lifestyle factors influenced SRH. It could therefore be useful for clinicians to consider these factors when providing care for patients born outside Sweden and resettled in areas with large numbers of immigrants.

\section{BACKGROUND}

According to the WHO, good health includes a balance between good objectively measurable and good subjectively experienced health. Whereas objective health is assessed by diagnosing diseases and measuring various clinical parameters, subjective health combines
Strengths and limitations of this study

- The questionnaire was available in different languages.

- Study included two healthcare centres catchment areas with a large number of immigrants.

- Non-random sampling limited the ability to draw conclusions.

- Those born outside Sweden were grouped together regardless of place of birth, potentially masking inequalities by place of birth.

- The study did not include information on cultural perceptions about health.

the physical, mental and social well-being of the individual. ${ }^{1}$ Self-rated health (SRH) has emerged as a unified, reliable measure of subjective health status that can provide valuable information and serve as a complement to objective health measures. ${ }^{2-4} \mathrm{SRH}$ is widely used in the field of public health, including national and international health surveys. ${ }^{5}$ Prior studies have shown that SRH is an independent predictor of mortality. ${ }^{467}$ It is associated with higher rates of mortality from numerous diseases, including cardiovascular diseases ${ }^{8}$ and diabetes, as well as allcause mortality. ${ }^{9}$ A meta-analysis from 2006 found that people who reported their health as fair or bad had a twofold higher risk of allcause mortality than those who reported their health as good. ${ }^{7}$

$\mathrm{SRH}$ is influenced by many factors. Examples include gender, ${ }^{10}$ socioeconomic status $(\mathrm{SES})^{11}$ and age. ${ }^{12}$ Women, people with low SES and older adults are more likely to report poor health. Lifestyle factors such as obesity, physical inactivity and smoking are also related to poor SRH. ${ }^{11} 13$ Furthermore, the way people rate their health in relation to 
self-reported diseases or functional ability seems to vary by country, as shown in a comparative study of people in Finland, Sweden, Spain, the Netherlands and Israel. ${ }^{12}$ However, some indicators seem to be significantly associated with SRH regardless of country of origin, including marital status, hypertension, stroke, diabetes, cancer, musculoskeletal diseases and activities of daily living. ${ }^{12}$

The factors that potentially influence how people rate their health differ from one individual to another, and even those with similar levels of objective ill health can perceive their health differently. A study of young people with type 1 diabetes mellitus found that participants varied in their SRH even after adjusting for multiple risk factors. ${ }^{14}$ Similarly, studies have found discrepancies in SRH among people with hypertension ${ }^{15}$ and advanced cancer. ${ }^{16}$

Immigrants make up a growing portion of the Swedish population, currently over $20 \% .{ }^{17}$ In 2016 , almost $80 \%$ of the population growth in Sweden resulted from immigration. Prior studies suggest that immigrants in Sweden generally have lower SRH than their Swedish-born counterparts. ${ }^{1819}$ Many studies on SRH in immigrant groups in Sweden focus on Finnish immigrants, ${ }^{2021}$ as they constitute one of the largest immigrant groups in the country. Similarly, studies have been conducted on immigrants from other European countries living in Sweden. ${ }^{1822}$ According to such studies, people born in Finland, Eastern Europe and Southern Europe living in Sweden rate their health poorer than those born in Sweden. ${ }^{20}{ }^{23}$ A similar pattern has been observed in immigrants from outside Europe, including adolescent boys, ${ }^{24}$ immigrants from the Middle East $^{25}$ and Assyrians with diabetes from Turkey. ${ }^{26}$

Research also shows that immigrants are more vulnerable to diseases than the native-born populations. ${ }^{27-29}$ This raises the question of whether differences in SRH could be explained by differences in objective health status. However, in previous studies, the inclusion of diseases has not eliminated the differences in SRH between foreign-born and native-born populations. In addition, a study comparing Kurdish immigrants to people born in Sweden found that the immigrants were more likely to report lower SRH despite comparable objective health, including chronic diseases, eczema, psoriasis, urinary tracts complaints and diabetes. ${ }^{26}$

Comparison between studies of SRH in immigrants versus native populations is made difficult by differences in study populations and methodological approaches. For instance, many previous studies in Sweden focus on middle-aged and older adults which limits their representativeness. According to Statistics Sweden, people between the ages of 18 and 35 years make up around $20 \%$ of the total immigrant population. ${ }^{30}$ This group therefore needs to be included when studying immigrants' health.

There is a gap in knowledge about the SRH of people living in Sweden who were born outside Sweden, particularly those born in the Middle East, Asia and Africa-a group with a high risk of developing pre-diabetes and diabetes. ${ }^{31}{ }^{32}$ More information about SRH in this group has the potential to improve healthcare services for these people.

\section{Aims}

The first aim of the current study was to determine the extent of the relationship between place of birth and SRH in primary healthcare patients born outside Sweden and those born in Sweden. The second aim of the study was to investigate whether socioeconomic and lifestyle factors explained any differences.

\section{METHODS}

The study design was cross-sectional.

\section{Data source}

Data were drawn from the "4D Diabetes Project: Screening and Treatment of Prediabetes and Diabetes in Primary Care - A Pilot Study', a large study conducted by Karolinska Institutet and the Stockholm County Council. The overall aim of the 4D Diabetes Project was to develop methods and procedure for early identification and/ or prevention of pre-diabetes and diabetes in people at high risk for those diseases. People born in the Middle East, Asia and Africa who live in Sweden have a higher risk of developing pre-diabetes and diabetes than native Swedes and develop diabetes on an average of 10 years earlier. $^{31}{ }^{32}$ Two areas with large populations of immigrants-in particular, immigrants born in the Middle East and Asia-were selected for the 4D Diabetes Project: Flemingsberg and Jakobsberg. ${ }^{30}$ Inclusion criteria for the 4D Diabetes Project were as follows: attending an academic primary healthcare centre in Flemingsberg or Jakobsberg during the period between 2013 and 2015, being between the ages of 18 and 74 years and being either a first-generation or second-generation immigrant or a person born in Sweden whose parents were born in Sweden. Patients with a diagnosis of diabetes were excluded from the study. The project aimed to consecutively recruit patients attending participating healthcare centres during the study period. All patients who fulfilled the study criteria were asked whether or not they wished to take part in the study. Information on the total number eligible patients who were asked to participate was not recorded. A total of 830 patients (389 from Flemingsberg and 441 from Jakobsberg) from 69 countries (including Sweden) agreed to participate and were included in the project. A total of $56.9 \% \quad(n=469)$ were born outside Sweden and $42.1 \%(n=356)$ were born in Sweden. The biggest groups were from Turkey $(n=86)$, Iran $(n=52)$, Iraq $(n=48)$, Finland $(n=39)$, Bangladesh $(n=24)$, Chile $(n=23)$ and Syria $(n=20)$. Five people in the $4 D$ Diabetes Project were missing information about their place of birth. The final sample size in the current analysis was thus 825 .

\section{Data collection}

The data were collected via face-to-face interviews at the academic primary healthcare centres in Flemingsberg 
and Jakobsberg. The interviews lasted approximately 15 to $20 \mathrm{~min}$ and were conducted in a separate room at the centres to maintain privacy for the participants. The questionnaire was available in Swedish, Arabic, Persian and Turkish.

\section{Patient and public involvement}

Neither patients nor the public were involved in the design of the study which was developed on the basis of previous research as well as the clinical experience of members of the 4D Diabetes Project group. Patients who met the inclusion criteria were provided with written and verbal information about the study and actively chose whether or not they wished to participate. The results of the study will be disseminated via seminars for healthcare professionals and patients at academic primary healthcare centres in the Stockholm region, including the participating centres. Centres across the Stockholm region will also receive short written summaries of the results.

\section{Outcome variable}

$S R H$ was assessed using a single question, "How would you rate your general state of health?" There were five response alternatives as recommended by WHO, ranging from 'very good' to 'very bad'. ${ }^{5}$ Responses were dichotomised in the analysis. Those who chose the alternatives 'very good' or 'good' were considered to have optimal SRH, whereas those who chose 'fair', 'bad' or 'very bad' were considered to have suboptimal SRH. This classification has been used in previous studies. ${ }^{19} 33$

\section{Independent variable}

Place of birth was the independent variable in this study. Place of birth was divided into two categories, 'born outside Sweden' and 'born in Sweden'. The first category included immigrants from all countries and the second category included those born in Sweden whose parents were born in Sweden.

\section{Explanatory variables}

The explanatory variables included in the study were sex (male or female), age, SES and lifestyle factors. Patients were divided into two age groups, 18-44 and 45-74 years. We included three measures of SES. The first, educational level, was divided into 9 or fewer years, 10-12 years and more than 12 years. The second, employment status, was divided into employed, unemployed (including homemakers) or other (retired/student). The third, marital status, was divided into married/cohabiting or single (divorced or separated/widowed). Two lifestyle factors were included in the study. The first, physical activity, was based on self-reported time spent in any kind of physical activity per week. It included five response alternatives divided into four categories in our study: $<30 \mathrm{~min}, 30-60 \mathrm{~min}$, 60-90 min and $>90 \mathrm{~min}$. The second lifestyle factor was smoking. In the current study, patients were divided into non-smokers, former smokers and current smokers.

\section{Statistical analysis}

Descriptive statistics were used to assess the study population's characteristics by place of birth. For the categorical variables, that is, sex, educational level, employment status, marital status, physical activity and smoking, the differences in percentages were compared using the $\chi^{2}$ test. A $p$ value of $<0.05$ was considered statistically significant. Logistic regression was performed to determine the association between low SRH in those born outside Sweden and the explanatory variables. Those born in Sweden were used as the reference group. The results are presented as ORs with 95\% CIs. The statistical analyses were performed with STATA V.14 (StataCorp).

\section{Ethical considerations}

The cross-sectional nature of this study limited the potential ethical problems, as there were no interventions that could have resulted in psychological or physical harm to the participants. Potential participants were provided with written and verbal information about the study and informed that participation was voluntary and that they had the right to withdraw from the study whenever they wished without facing any consequences. Since many potential participants were born abroad and had limited or no knowledge of Swedish, the written and verbal study information and questionnaires were available in Swedish, Arabic, Persian and Turkish. All participants provided written informed consent before inclusion in the study. Individual identities were replaced with code numbers prior to analysing the data. The link between the code number and identities is stored in a locked vault in keeping with the ethical rules of Karolinska Institutet.

The results of this study can help form the basis of future studies to deepen our understanding of SRH and could thus benefit patients in the future, including but not limited to our study participants.

\section{RESULTS}

\section{Demographic characteristics}

Demographic characteristics of the study population by place of birth are shown in table 1. A total of 825 patients participated; $56.8 \%$ were born outside Sweden and $43.2 \%$ were born in Sweden. No significant differences were found between the two groups with regard to sex or marital status. Those born outside Sweden were significantly younger, had a higher educational level and were less physically active. On the other hand, a significantly higher percentage of those born outside Sweden than those born in Sweden were current smokers. The mean age of those born outside Sweden was 46 and those born in Sweden was 52. More than half the participants had more than 12 years of education $(54.0 \%)$. More than two-thirds of the participants were married/cohabiting (70.0\%). The majority of the participants reported being physically active $(63.3 \%)$, and more than half were employed $(53.5 \%)$. The percentage of people born outside Sweden 
Table 1 Characteristics of the study populationt in total and by place of birth

\begin{tabular}{|c|c|c|c|c|c|}
\hline Variables & Category & Total & Born outside Sweden & Born in Sweden & $P$ value \\
\hline Sample size, n (\%) & & $825(100)$ & $469(56.8)$ & $356(43.2)$ & \\
\hline \multirow[t]{2}{*}{ Age, mean (SD) } & & $49(0.5)$ & $46(12.8)$ & $52(16.4)$ & $<0.0001 \mp \S$ \\
\hline & 45-74 years & $506(61.0)$ & $260(55.4)$ & $244(68.7)$ & \\
\hline Sex, n (\%) & Female & $475(57.2)$ & $269(57.4)$ & $203(57.0)$ & $0.924 \ddagger$ \\
\hline $\mathrm{SRH}^{*}, \mathrm{n}(\%)$ & Suboptimal & $392(47.7)$ & $226(48.3)$ & $150(42.4)$ & \\
\hline \multirow[t]{8}{*}{ SES, n (\%) } & Educational level $^{\star *}$ & & & & $<0.0001 \ddagger$ \\
\hline & $\leq 9$ years & $148(18.0)$ & $97(20.8)$ & $51(14.3)$ & \\
\hline & $10-12$ years & $230(28.0)$ & $98(21.0)$ & $132(37.1)$ & \\
\hline & Unemployed & $102(12.6)$ & 73 (15.9) & $29(8.3)$ & \\
\hline & Other & 274 (33.9) & $127(27.6)$ & $147(42.1)$ & \\
\hline & Marital status & & & & $0.066 \neq$ \\
\hline & Single & $248(30.1)$ & $129(27.5)$ & $119(33.4)$ & \\
\hline & Married/cohabiting & 577 (69.9) & $340(72.5)$ & $237(66.6)$ & \\
\hline \multirow[t]{4}{*}{ Lifestyle factors, n (\%) } & Physical activity ${ }^{\star \star \star \star}$ & & & & $<0.0001 \ddagger$ \\
\hline & $<30$ min & $103(12.5)$ & $80(17.1)$ & $23(6.5)$ & \\
\hline & $30-60 \min$ & $105(12.7)$ & $76(16.2)$ & $29(8.1)$ & \\
\hline & $60-90 \min$ & 95 (11.5) & $58(12.4)$ & $37(10.4)$ & \\
\hline
\end{tabular}

*3 missing, ${ }^{\star *} 2$ missing, ${ }^{\star * \star} 16$ missing, ${ }^{\star * \star *} 1$ missing, ${ }^{\star * \star \star * 2}$ missing.

†The study population consisted of the 4D Diabetes Project population minus five individuals missing data on place of birth. łBold numbers are significant.

$\S X^{2}$ test.

SES, socioeconomic status; $\mathrm{SRH}$, self-rated health.

Table 2 Distribution of optimal and suboptimal self-rated health $(\mathrm{SRH})$ in the study population* by place if birth and sex $(n=822 \dagger)$

\begin{tabular}{|c|c|c|c|c|c|}
\hline \multirow[b]{2}{*}{ Characteristic } & \multicolumn{2}{|c|}{ Optimal SRH, n=392 } & \multicolumn{2}{|c|}{ Suboptimal SRH, n=430 } & \multirow[b]{2}{*}{$P$ value } \\
\hline & Female & Male & Women & Men & \\
\hline In total, n (\%) & $232(53.3)$ & $198(46.1)$ & $239(61.0)$ & 153 (39.0) & 0.042 \\
\hline Born in Sweden & $84(56.0)$ & $66(44.0)$ & 119 (58.3) & $85(41.7)$ & 0.661 \\
\hline
\end{tabular}

Bold numbers are significant.

${ }^{*}$ The study population consisted of the 4D Diabetes Project population minus five individuals missing data on place of birth.

†Data on sex were missing for three individuals. 
with optimal SRH $(51.7 \%)$ was lower than in those born in Sweden $(57.6 \%)$.

Table 2 presents the distribution of SRH by place of birth and sex. There were statistically significant differences in SRH between women and men in the study population as a whole and in people born outside Sweden. No significant sex differences were observed in people born in Sweden.

\section{LOGISTIC REGRESSION}

Table 3 presents the ORs of suboptimal SRH in patients born outside Sweden and patients born in Sweden in three models. Model 1 was adjusted for age and sex; model 2, for age, sex and SES (employment status, educational level and marital status); and model 3, for age, sex, SES and lifestyle factors (physical activity and smoking). The crude OR of reporting suboptimal health was 1.46 (95\% CI 1.10 to 1.92) for those born outside Sweden (reference group: those born in Sweden). This relationship increased to 1.50 after controlling for educational level, employment and marital status (95\% CI 1.11 to 2.02) and decreased to 1.36 but remained significant after adjustment for physical activity and smoking (95\% CI, 1.00 to $1.85)$.

\section{DISCUSSION}

In this study, we aimed to assess and compare the association between SRH and place of birth in primary healthcare patients born outside Sweden and in Sweden. Those born outside Sweden had significantly lower SRH than their Swedish-born counterparts. This result agrees with the results of previous studies that investigated SRH in patients born outside Sweden, especially those born in the Middle East. ${ }^{22} 26$

Chronic diseases are more prevalent in non-European immigrants to Europe than in native Europeans. ${ }^{34}{ }^{35}$ The presence of chronic diseases can alter quality of life which could potentially negatively impact SRH. However, we were unable to explore this issue because of limited data. Additionally, psychological status can affect SRH. ${ }^{36} 37$ Psychological distress can be triggered by various situations. Migration per se is a stressful process. ${ }^{38}$ Immigrants can also be affected by past traumatic experiences; ongoing stress and worry about the situation in their home country, including family left behind; and discrimination in the host country. ${ }^{37}$ They can also face obstacles such as the need to learn a new language and to translate educational and professional competencies to those of the host country. ${ }^{39}$

The finding that SRH differs significantly between immigrants and their Swedish-born counterparts agrees with results of several previous Swedish studies. ${ }^{19} 2640$ For example, our analyses confirm the results of a study of nearly 9000 older adult immigrants (age 55-74 years) in Sweden from a variety of ethnic backgrounds ${ }^{22}$ but extend the findings to a larger age range. Similarly, the current study extends the results of a study of ethnicity and low SRH in Assyrians living in the town of Södertälje, which focused solely on people with diabetes, did not include lifestyle factors as a possible confounder and collected data in a different way. ${ }^{2641}$

Several studies carried out in Sweden have had similar results despite differences in data collection methods. The current study, carried out with face-to-face interviews and questionnaires in several languages; the study of Assyrians in Södertälje, carried out using an interpreter $^{26}$ and a study of immigrants in Malmö, carried out with mailed questionnaires that were not translated into immigrants' native languages ${ }^{24}$ all found that immigrants reported poorer health than native Swedes.

In a large cross-sectional study of immigrants from Turkey, Iran and Poland, differences between the immigrants and native Swedes in reporting significantly poorer health disappeared after accounting for SES, knowledge of the Swedish language and discrimination. ${ }^{39}$ In our study, as in the study of older immigrants in Malmö, ${ }^{18}$ the differences in SRH between groups remained statistically significant after adjustment for SES.

In contrast to our study, a study of 93 age-matched and sex-matched pairs of native born Swedes and people from Somalia and Iraq who had recent permanent residence permits found that the immigrants did not have worse subjective physical or psychological health than the Swedish controls. ${ }^{35}$ The authors of the case-control study suggested that a number of factors may have contributed to this finding, including a healthy refugee effect, the environment of the study location and the relatively high levels of education in the men from Iraq. However, more than half of those born abroad in our study (58.2\%) had more than 12 years of education, and we still found a significant difference in SRH between those born abroad and native-born Swedes.

As in our study of people in two largely immigrant neighbourhoods in the Stockholm area, a study of European and non-European immigrants in a single neighbourhood in Denmark found that immigrants had lower SRH than the native-born people in the study population. ${ }^{42}$ Unlike in our study, however, the authors of the Danish study found that immigrants had fewer life resources and that this explained the results. Life resources in that study comprised a multiple factors, including 'living with others', 'has children', 'has studied beyond primary school', 'has occupational income' and more. We found fewer but similar SES factors in our study, including education, employment and marital status. They had a significant impact on the results but did not fully explain the differences between immigrants and native Swedes.

A Swedish study of patients with type 2 diabetes that had a study population similar to ours with regard to countries of birth, found a similar pattern of $\mathrm{SRH} .{ }^{26}$ That is, the patients in the previous study who were born in the Middle East had lower SRH than the patients born in Sweden. As in our study, in the previous study, statistically significant difference in self-rated general health 
Table 3 Prevalence ratios (ORs) and their 95\% Cls of suboptimal self-rated health for those born outside Sweden*

\begin{tabular}{|c|c|c|c|c|}
\hline Variable & Crude OR & Model 1: +age, sex & $\begin{array}{l}\text { Model 2: +educ. level, } \\
\text { employment, marital status }\end{array}$ & $\begin{array}{l}\text { Model 3: +physical } \\
\text { activity, smoking }\end{array}$ \\
\hline Born in Sweden & Reference & Reference & Reference & Reference \\
\hline Born outside Sweden & $\begin{array}{l}1.46 \\
1.10-1.92\end{array}$ & $\begin{array}{l}\mathbf{1 . 4 8} \\
1.12-1.97\end{array}$ & $\begin{array}{l}\mathbf{1 . 5 0} \\
1.11-2.02\end{array}$ & $\begin{array}{l}\mathbf{1 . 3 6} \\
1.00-1.85\end{array}$ \\
\hline \multicolumn{5}{|l|}{ Age } \\
\hline $18-44$ years & & Reference & Reference & Reference \\
\hline $45-74$ years & & $\begin{array}{l}0.94 \\
0.70-1.24\end{array}$ & $\begin{array}{l}1.00 \\
0.74-1.37\end{array}$ & $\begin{array}{l}0.94 \\
0.68-1.29\end{array}$ \\
\hline \multicolumn{5}{|l|}{ Sex } \\
\hline Female & & Reference & Reference & Reference \\
\hline Male & & $\begin{array}{l}1.34 \\
1.02-1.78\end{array}$ & $\begin{array}{l}1.16 \\
0.87-1.55\end{array}$ & $\begin{array}{l}1.18 \\
0.88-1.60\end{array}$ \\
\hline \multicolumn{5}{|l|}{ Educational level } \\
\hline$\leq 9$ years & & & Reference & Reference \\
\hline $10-12$ years & & & $\begin{array}{l}1.40 \\
0.90-2.17\end{array}$ & $\begin{array}{l}1.30 \\
0.83-2.02\end{array}$ \\
\hline$>12$ years & & & $\begin{array}{l}1.57 \\
1.05-2.33\end{array}$ & $\begin{array}{l}1.46 \\
0.97-2.20\end{array}$ \\
\hline \multicolumn{5}{|l|}{ Employment status } \\
\hline Employed & & & Reference & Reference \\
\hline Unemployed & & & $\begin{array}{l}0.47 \\
0.29-0.74\end{array}$ & $\begin{array}{l}0.47 \\
0.29-0.75\end{array}$ \\
\hline Other & & & $\begin{array}{l}0.76 \\
0.55-1.05\end{array}$ & $\begin{array}{l}0.75 \\
0.54-1.04\end{array}$ \\
\hline \multicolumn{5}{|l|}{ Marital status } \\
\hline Married/cohabiting & & & Reference & Reference \\
\hline Single & & & $\begin{array}{l}0.61 \\
0.45-0.83\end{array}$ & $\begin{array}{l}0.62 \\
0.45-0.86\end{array}$ \\
\hline \multicolumn{5}{|l|}{ Physical activity } \\
\hline$<30$ min & & & & Reference \\
\hline $30-60 \min$ & & & & $\begin{array}{l}1.96 \\
1.09-3.52\end{array}$ \\
\hline $60-90 \mathrm{~min}$ & & & & $\begin{array}{l}2.10 \\
1.13-3.79\end{array}$ \\
\hline$>90$ min & & & & $\begin{array}{l}2.80 \\
1.74-4.50\end{array}$ \\
\hline \multicolumn{5}{|l|}{ Smoking } \\
\hline Non-smoker & & & & Reference \\
\hline Former smoker & & & & $\begin{array}{l}0.99 \\
0.70-1.41\end{array}$ \\
\hline Current smoker & & & & $\begin{array}{l}1.01 \\
0.67-1.50\end{array}$ \\
\hline
\end{tabular}

Bold numbers are significant.

${ }^{*}$ The study population consisted of the 4D Diabetes Project population.

were not explained by socioeconomic or lifestyle factors. Future studies could focus on lifestyle, mental health, stress and comorbidity as potential explanations for SRH in people born in Middle East and Africa with a high risk of diabetes.
SRH is an easy item to collect since it is assessed through a single question. Despite that, it has an impact on a major heath outcome (mortality). Efforts to understand SRH and the factors related to can benefit the healthcare system in many ways. The current study adds support to 
previous research that found lower SRH in immigrant than in native populations. In our study, as in others, socioeconomic and lifestyle factors influenced SRH. It could therefore be useful for clinicians to consider these factors when providing care for patients born outside Sweden and resettled in areas with large numbers of immigrants. Future studies should further investigate what lies behind the discrepancies in SRH in immigrant and native-born primary healthcare patients.

The current study has several strengths and limitations. One strength of the study was the way data were collected. The questionnaire was available in different languages spoken by many people living in the study areas: Arabic, Persian, Turkish and Swedish. Another strength of the study was that the catchment areas of the healthcare centres in the current study included a large number of immigrants. Sampling was non-random, which limited our ability to draw conclusions. Another limitation of the study was grouping together those born outside Sweden regardless of the place of birth which might have masked potential inequalities. Furthermore, even people from the same country can come from different ethnic and religious groups, different cultures and different socioeconomic and political situations. Therefore, the final limitation of this study is the lack of information on cultural perceptions about health and lifestyle in the study population which might partially explain the low SRH in patients born outside Sweden.

\author{
Author affiliations \\ ${ }^{1}$ Academic Primary Healthcare Centre, Region Stockholm, Stockholm, Sweden \\ ${ }^{2}$ Division of Family Medicine and Primary Care, Department of Neurobiology, \\ Science and Society, Karolinska Institutet, Stockholm, Sweden \\ ${ }^{3}$ Study Programme in Medicine, Karolinska Institute, Stockholm, Sweden \\ ${ }^{4}$ Jakobsberg Academic Primary Healthcare, Stockholm, Sweden \\ ${ }^{5}$ Endocrine and Diabetes Unit, Department of Molecular Medicine and Surgery, \\ Karolinska institutet, Stockholm, Sweden
}

Acknowledgements The authors wish to acknowledge all patients who participated in the study and the heads of the academic primary healthcare centres who gave permission to collect data in the waiting rooms of the centres.

Contributors MT, AA and HS designed the study. CGÖ, KHS, FL and MT were responsible for data collection. MT, AA and HS wrote the first draft of the manuscript and conducted analyses. CGÖ, KHS and FL contributed to the choice of analytical methods. MT extracted the data. MT and AA conducted the initial analyses and interpretation of the results. All authors contributed to the analyses and editing of the manuscript and approval the final version.

Funding The study was based on data from 4D Diabetes Project, which received financial support from the Stockholm County Council and Karolinska Institutet. The funders played no role in the design or conduct of the study, as the 4D Diabetes Project, including the current study, was designed by 4D Diabetes Project research team.

Competing interests None declared.

Patient consent for publication Not required.

Ethics approval The present study was approved by the Ethical Review Board in Stockholm (reference number for 4D Diabetes Project: 2013/2303-31/3).

Provenance and peer review Not commissioned; externally peer reviewed.

Data availability statement Data are available upon reasonable request.

Open access This is an open access article distributed in accordance with the Creative Commons Attribution Non Commercial (CC BY-NC 4.0) license, which permits others to distribute, remix, adapt, build upon this work non-commercially, and license their derivative works on different terms, provided the original work is properly cited, appropriate credit is given, any changes made indicated, and the use is non-commercial. See: http://creativecommons.org/licenses/by-nc/4.0/.

ORCID iDs

Marina Taloyan http://orcid.org/0000-0002-2773-8975

Claes-Goran Ostenson http://orcid.org/0000-0003-2888-9932

\section{REFERENCES}

1 Hardy MA, Acciai F, Reyes AM. How health conditions translate into self-ratings: a comparative study of older adults across Europe. $J$ Health Soc Behav 2014;55:320-41.

2 Wu S, Wang R, Zhao Y, et al. The relationship between self-rated health and objective health status: a population-based study. $B M C$ Public Health 2013;13:320.

3 Jürges $\mathrm{H}$, Avendano M, Mackenbach JP. Are different measures of self-rated health comparable? an assessment in five European countries. Eur J Epidemiol 2008;23:773-81.

4 Jylhä M. What is self-rated health and why does it predict mortality? towards a unified conceptual model. Soc Sci Med 2009;69:307-16.

5 de Bruin A, Picavet HS, Nossikov A. Health interview surveys. towards international harmonization of methods and instruments. WHO Reg Publ Eur Ser 1996;58:1-161.

6 DeSalvo KB, Fan VS, McDonell MB, et al. Predicting mortality and healthcare utilization with a single question. Health Serv Res 2005;40:1234-46.

7 DeSalvo KB, Bloser N, Reynolds K, et al. Mortality prediction with a single General self-rated health question. A meta-analysis. J Gen Intern Med 2006;21:267-75.

8 Mavaddat N, Parker RA, Sanderson S, et al. Relationship of selfrated health with fatal and non-fatal outcomes in cardiovascular disease: a systematic review and meta-analysis. PLoS One 2014;9:e103509.

9 McEwen LN, Kim C, Haan MN, et al. Are health-related qualityof-life and self-rated health associated with mortality? insights from translating research into action for diabetes (triad). Prim Care Diabetes 2009;3:37-42.

10 Cau BM, Falcão J, Arnaldo C. Determinants of poor self-rated health among adults in urban Mozambique. BMC Public Health 2016;16:856.

11 Molarius A, Berglund K, Eriksson C, et al. Socioeconomic conditions, lifestyle factors, and self-rated health among men and women in Sweden. The European Journal of Public Health 2007;17:125-33.

12 Bardage C, Pluijm SMF, Pedersen NL, et al. Self-Rated health among older adults: a cross-national comparison. Eur J Ageing 2005;2:149-58.

13 Svedberg P, Bardage C, Sandin S, et al. A prospective study of health, life-style and psychosocial predictors of self-rated health. Eur $J$ Epidemiol 2006;21:767-76.

14 Huang G-H, Palta M, Allen C, et al. Self-Rated health among young people with type 1 diabetes in relation to risk factors in a longitudinal study. Am J Epidemiol 2004;159:364-72.

15 Ma C, Zhou W, Huang C, et al. A cross-sectional survey of self-rated health and its determinants in patients with hypertension. App/ Nurs Res 2015;28:347-51.

16 Shadbolt B, Barresi J, Craft P. Self-Rated health as a predictor of survival among patients with advanced cancer. $J$ Clin Oncol 2002;20:2514-9.

17 Statistics Sweden, 2017. Available: http://www.scb.se/hitta-statistik/ sverige-i-siffror/manniskorna-i-sverige/in-och-utvandring/

18 Lindström M, Sundquist J, Ostergren PO. Ethnic differences in self reported health in Malmö in southern Sweden. J Epidemiol Community Health 2001;55:97-103.

19 Taloyan M, Sundquist J, Al-Windi A. The impact of ethnicity and self-reported health on psychological well-being: a comparative study of Kurdish-born and Swedish-born people. Nord J Psychiatry 2008;62:392-8.

20 Westman J, Martelin T, Härkänen T, et al. Migration and self-rated health: a comparison between Finns living in Sweden and Finns living in Finland. Scand J Public Health 2008;36:698-705.

21 Kulla GE, Ekman S-L, Heikkilä AK, et al. Differences in self-rated health among older immigrants--a comparison between older Finland-Swedes and Finns in Sweden. Scand J Public Health 2010;38:25-31.

22 Pudaric S, Sundquist J, Johansson S-E. Country of birth, instrumental activities of daily living, self-rated health and mortality: a Swedish population-based survey of people aged 55-74. Soc Sci Med 2003;56:2493-503. 
23 Leão TS, Sundquist J, Johansson S-E, et al. The influence of age at migration and length of residence on self-rated health among Swedish immigrants: a cross-sectional study. Ethn Health 2009:14:93-105.

24 Lindström M, Modén B, Rosvall M. Country of birth, parental background and self-rated health among adolescents: a populationbased study. Scand J Public Health 2014;42:743-50.

25 Bennet L, Agardh C-D, Lindblad U. Cardiovascular disease in relation to diabetes status in immigrants from the middle East compared to native Swedes: a cross-sectional study. BMC Public Health 2013;13:1133.

26 Taloyan M, Wajngot A, Johansson S-E, et al. Poor self-rated health in adult patients with type 2 diabetes in the town of Södertälje: a crosssectional study. Scand J Prim Health Care 2010;28:216-20.

27 Koochek A, Mirmiran P, Azizi T, et al. Is migration to Sweden associated with increased prevalence of risk factors for cardiovascular disease? Eur $J$ Cardiovasc Prev Rehabil 2008;15:78-82.

28 Koochek A, Montazeri A, Johansson S-E, et al. Health-Related quality of life and migration: a cross-sectional study on elderly Iranians in Sweden. Health Qual Life Outcomes 2007;5:60.

$29 \mathrm{Li} \mathrm{X}$, Sundquist J, Sundquist K. Risks of rheumatic diseases in firstand second-generation immigrants in Sweden: a nationwide followup study. Arthritis Rheum 2009;60:1588-96.

30 Statistics S, 2017. Available: http://www.scb.se/hitta-statistik/ statistik-efter-amne/befolkning/befolkningens-sammansattning/ befolkningsstatistik/

31 Wändell P-E, Wajngot A, de Faire U, et al. Increased prevalence of diabetes among immigrants from non-European countries in 60-yearold men and women in Sweden. Diabetes Metab 2007;33:30-6.

32 Wändell PE, Gåfvels C. High prevalence of diabetes among immigrants from non-European countries in Sweden. Prim Care Diabetes 2007;1:13-16.
33 Mohseni M, Lindström M. Ethnic differences in anticipated discrimination, generalised trust in other people and self-rated health: a population-based study in Sweden. Ethn Health 2008;13:417-34.

34 Löfvander M, Taloyan M. Pain intensity and severe pain in young immigrant patients with long-standing back pain. European Spine Journal 2008;17:89-96.

35 Löfvander M, Rosenblad A, Wiklund T, et al. A case-control study of self-reported health, quality-of-life and general functioning among recent immigrants and age- and sex-matched Swedish-born controls. Scand J Public Health 2014;42:734-42.

36 Bhugra D. Migration and mental health. Acta Psychiatr Scand 2004;109:243-58.

37 Bhugra D. Migration and depression. Acta Psychiatr Scand 2003;108:67-72.

38 Bhugra D. Migration and schizophrenia. Acta Psychiatr Scand 2000;102:68-73.

39 Wiking E, Johansson SE, Ethnicity SJ. Ethnicity, acculturation, and self reported health. A population based study among immigrants from Poland, Turkey, and Iran in Sweden. J Epidemiol Community Health 2004;58:574-82.

40 Wiking E, Johansson S-E, Sundquist J. Ethnicity, acculturation, and self reported health. A population based study among immigrants from Poland, Turkey, and Iran in Sweden. J Epidemiol Community Health 2004;58:574-82.

41 Taloyan M, Wajngot A, Johansson S-E, et al. Cardiovascular risk factors in Assyrians/Syrians and native Swedes with type 2 diabetes: a population-based epidemiological study. Cardiovasc Diabetol 2009;8:59.

42 Andersen PT, Bak CK, Vangsgaard S, et al. Self-Rated health, ethnicity and social position in a deprived neighbourhood in Denmark. Int J Equity Health 2011;10:5. 